\title{
Knowledge level and prevetive strategies on penile cancer in health area degree students
}

\begin{abstract}
Aim: To evaluate the level of knowledge of the students of the Higher Education in the health area of an IES (Higher Education Institution) of a city in the interior of the State of Goiás, about penile cancer and to identify the strategies adopted by the population to prevent carcinoma penile.
\end{abstract}

Method: This is a field-based, evaluative, exploratory, descriptive, cross-sectional, quantitative approach.

Results: we found the predominance of students with high level of knowledge $(72.5 \%)$ on penile cancer, followed by those with a medium level of knowledge (26.1) on the subject. The most frequent attitudes for penile cancer prevention were: cleaning the penis daily with soap and water, using condoms in sexual relations; performing penis hygiene after sexual intercourse and masturbation; trying to have good hygiene habits, taking medical consultation when they felt something and inspect the penile in the shower.

Conclusion: we found a high level of knowledge regarding the penile cancer prevention. Early detection of condom use, daily hygiene and non-promiscuity of sexual partners are relevant points in the prevention and detection of the disease.

Keywords: Penile Neoplasms, Public Health, Area Health Education Centers, Health Education, Students, Health Occupations

\author{
Volume 9 Issue 6 - 2018
}

\section{lel Marciano de Moraes-Filho,' Maria Rubiene Timoteo Nery, ${ }^{2}$ Sheila da Silva Santos, ${ }^{3}$ Maria Fernanda Rocha Proença, Carla Chiste Tomazoli Santos, ${ }^{4}$ Rodrigo Marques da Silva ${ }^{5}$}

'Enfermeiro. Especialista em Enfermagem do trabalho, Mestre em Ciências ambientais e Saude, Docente da

${ }^{2}$ Faculdade Sena Aires, Valparaiso de Goiás, Brasil

${ }^{3}$ Acadêmica de Enfermagem, Faculdade Sena Aires, Valparaiso de Goiás, Brasil

${ }^{4}$ Fisioterapeuta, Especialista em Saúde perinatal desenvolvimento do bebê, Docente da Faculdade Sena Aires. Valparaiso de Goiás, Brasil

${ }^{5}$ Fisioterapeuta Neurofuncional, Mestre em Ciências da Saúde. Docente da Faculdade Sena Aires, Valparaiso de Goiás, Brasil

Correspondence: Rodrigo Marques da Silva, Fisioterapeuta Neurofuncional, Mestre em Ciências da Saúde.Docente da Faculdade Sena Aires,Valparaiso de Goiás, Goiás, Brasil, Email marpues-sm@hotmail.com

Received: June 01, 2017 | Published: November 16, 2018

\section{Introduction}

Penile cancer, although considered rare in developed countries, presents relevant incidence rates in Brazil. The increase in neoplasias in the male population is due to the adjustment of multiple factors, some of them environmental, genetic and lifestyle, such as smoking, sedentary lifestyle, poor diet, obesity, alcoholism, resulting from exposure to infectious agents, without condoms and with multiple partners. ${ }^{1,2}$ This amount of factors increases the risk of development of certain types of cancer, and the single reduction of only one of them may be limited to cover the effectiveness of precautionary actions. ${ }^{2}$ Amidst the clinical forms of cancers that often affect the male population, I emphasize penile cancer. An uncommon neoplasm in developed countries, unlike what occurs in regions of low socioeconomic class, as in most of the Brazilian Northeast. ${ }^{3}$ In Brazil, penile carcinoma is the fourth most common type of male cancer in the North and Northeast, simultaneously 5.7 and 5.3\%; in the CenterWest region takes eighth place and in the South and Southeast regions and occupies the top ten male neoplasms. ${ }^{4}$

The main risk factors are ineffective hygiene of the penis, phimosis, due to the hygiene difficulty caused by excess skin and HPV infection, however, it is correct to mention that the cancer remains with etiology not yet completely clarified. ${ }^{5}$ Researchers have pointed to the seriousness of good hygiene as a prevention factor for penile cancer and prove that sexually transmitted infections are linked to penile cancer, indicating that sexual intercourse with numerous partners without condoms is at high risk and contributes considerably to the increase of this neoplasm. ${ }^{6}$

Primary prevention through preventive measures through collective actions to educate and educate the population, especially in the male population and direct interventions in environmental and behavioral factors, from the early stages of life, simulate an admirable tool that can make possible a greater happening of practices preventive, not only preventing the appearance of neoplasm, but also substantially amortizing the proportion of cancer deaths. ${ }^{4}$

In this circumstance, the study is justified due to the great incidence of penile cancer in Midwest Brazil and therefore the various studies have reported the importance of the impact of transformations and modified behavioral patterns from childhood to adulthood and advise that the intercessions in the early stages of life have the capacity to be more effective than actions restricted to prevention, treatment and cure, the right to incidence and mortality from cancer in man. ${ }^{7}$ Therefore, stratifying the knowledge of these professionals who will eventually attend this public who may or may not be conducive to the development of penile cancer, relatively proportional to health education actions developed during the life of individuals. In this sense, we aimed to assess the knowledge level about penile cancer in health area degree students and to identify the strategies they adopt for penile carcinoma prevention.

\section{Method}

This is an exploratory, descriptive, cross-sectional, field-based, quantitative-based field survey conducted using a questionnaire on socioeconomic and demographic data, prepared by Guimaraes et al. in 2017 on the knowledge of the students of the Higher courses of nursing, pharmacy and physiotherapy of an HEI, a city in the interior of the State of Goiás, about penile cancer and the strategies adopted by the male population for the prevention of penile carcinoma. ${ }^{2}$ The 
study was conducted with 422 students from an HEI. The study included male and female students, aged 18 years and over, being regular students enrolled in HEI and who agreed to participate in the study. Students who were not properly enrolled, under the age of 18, students who were not enrolled in the HEI at the time of data collection, and those who did not agree to participate in the study were excluded from the study. Data collection took place between September and October 2018 through the application of a structured questionnaire for socioeconomic, demographic and knowledge assessment and prevention practices regarding penile cancer. ${ }^{2}$

For data analysis, the Excel for Windows version 2018 program was used to construct the database, after the spreadsheet was validated, the database was exported to the software program Statistical Package for Social Science (SPSS), version 18.0, the test was used Pearson's chi-square for categorical categorical or quantitative variables. Subsequently, we proceeded to discuss the findings based on the literature produced on the topic. The research project was approved by the Research Ethics Committee, with Certificate of Ethics Presentation (Certificado de Apresentação para Apreciação Ética (CAAE)) number 47445815.8.0000.5184. It should be noted that the researchers committed themselves to the norms advocated by the Resolution of the Brazilian National Health Council 466/12 and its complementary ones.

\section{Results}

At the beginning of the study, there were 806 students enrolled, being 367 in the nursing course, 250 in the pharmacy course and 189 in the physiotherapy course. Of these, 422, they returned the completed questionnaires, being $105(24.9 \%)$ of the pharmacy course, $209(49.5 \%)$ of nursing and $108(25.6 \%)$ of physiotherapy. Table 1 presents the socio-demographic and academic characterization of the students of the HEI courses.

Table I Sociodemographic and academic characterization of the students of the health area of an HEl in the interior of Goiás.Valparaiso de Goiás, 2018

\begin{tabular}{ll}
\hline Sociodemographic variables & $\mathbf{n}(\%)$ or Average (SD)* \\
\hline Sex & \\
Male & $114(27 \%)$ \\
Female & $308(73 \%)$ \\
Total & $422(100 \%)$ \\
Marital Status & \\
Single (a) & $27 \mathrm{I}(64,2 \%)$ \\
Married (a) & $113(26,82 \%)$ \\
Stable union & $23(5,52 \%)$ \\
Divorced & $13(3,12 \%)$ \\
Widower & $1(0,22 \%)$ \\
Religion & \\
Evangelical/Protestant & $121(28,7 \%)$ \\
Catholic & $174(41,2 \%)$ \\
Spiritist & $3(0,7 \%)$ \\
Other & $124(29,4 \%)$ \\
Number of children & $0,67(1,0)$ \\
Age & $26,85(7,65)$ \\
\hline
\end{tabular}

*Standard Deviation

There was predominance of students with a mean age of 26.85 years $(\mathrm{SD}=7.65)$, female $(73 \%)$, single $(64.2 \%)$, with approximately one child $(\mathrm{SD}=1.0)$, on average, Catholics $(41.2 \%)$ and enrolled in the nursing course (49.5\%). Table 2 shows the results of the assessment of knowledge of undergraduate health students on penile cancer.

Table 2 Assessment of knowledge of undergraduate health students about penile cancer.Valparaiso de Goiás, 2018. $(n=422)$

\begin{tabular}{|c|c|c|c|}
\hline Item & $\begin{array}{l}\text { Yes } \\
\mathrm{n}(\%)\end{array}$ & $\begin{array}{l}\text { No } \\
\text { n(\%) }\end{array}$ & $\begin{array}{l}\text { Don't } \\
\text { know } \\
\text { n(\%) }\end{array}$ \\
\hline $\begin{array}{l}\text { I- Penis cancer is found only in } \\
\text { individuals over the age of } 50(\mathrm{~F})\end{array}$ & $29(6,9)$ & $393(93,1)$ & 0 \\
\hline $\begin{array}{l}\text { 2- Lack of intimate hygiene on a daily } \\
\text { basis can lead to penile cancer }(\mathrm{V})\end{array}$ & $373(88,4)$ & $49(11,6)$ & 0 \\
\hline $\begin{array}{l}3 \text { - Penile lesions for a long time is } \\
\text { indicative of penile cancer }\end{array}$ & $312(73,9)$ & $110(26,1)$ & 0 \\
\hline $\begin{array}{l}\text { 4- HPV infection is considered a risk } \\
\text { factor for penile cancer }(V)\end{array}$ & $367(89,3)$ & $45(10,7)$ & 0 \\
\hline $\begin{array}{l}\text { 5- Sexual intercourse with several } \\
\text { partners without protection is a risk } \\
\text { factor (V) }\end{array}$ & $377(89,3)$ & $45(10,7)$ & 0 \\
\hline $\begin{array}{l}6 \text { - Penile cancer can lead to } \\
\text { amputation of the genital organ }(\mathrm{V})\end{array}$ & $386(91,5)$ & $36(8,5)$ & 0 \\
\hline $\begin{array}{l}\text { 7- Bleeding and bad smell in the } \\
\text { region of the penis is indicative of } \\
\text { cancer }(\mathrm{V})\end{array}$ & $310(73,5)$ & $\begin{array}{lrl}1 & 1 & 2 \\
(26,5) & \end{array}$ & 0 \\
\hline
\end{tabular}

It is observed that $93.1 \%$ of the participants disagree that penile cancer is only found in individuals older than 50 years; $88.4 \%$ understand that lack of intimate hygiene can lead to penile cancer; $73.9 \%$ report that the presence of penile lesions for a long time is indicative of penile cancer; $89.3 \%$ indicated that HPV infection is a risk factor for cancer; $89.3 \%$ state that having unprotected sex with a partner is a risk factor for penile cancer; $91.5 \%$ confirm that penile cancer can lead to amputation of the genital organ; and $73.5 \%$ agree that bleeding and stench in the penis region is indicative of cancer. In general, there was a predominance of correct answers in all the questions presented to undergraduate students. Figure 1 presents the evaluation of the level of knowledge of the students of the health area about penile cancer.

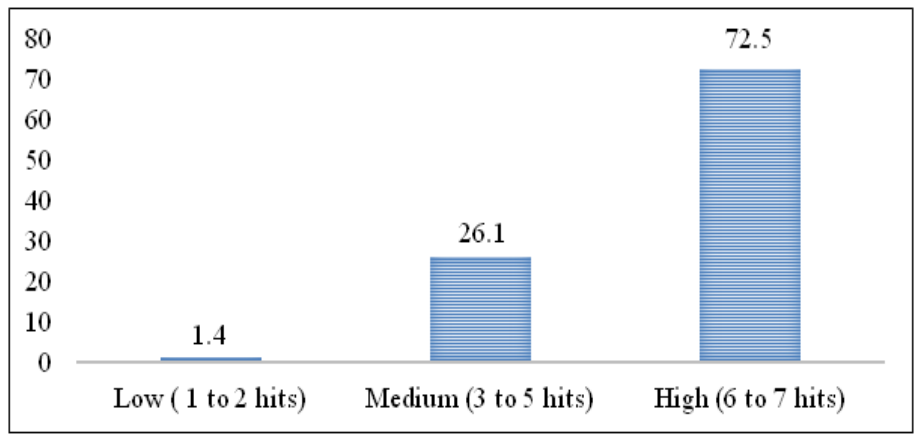

Figure I Level of knowledge of health students about penile cancer $(n=422)$.

The figure above shows the prevalence of students with a high level of knowledge $(72.5 \%)$ on penile cancer, followed by those with a medium level of knowledge (26.1) on the subject. Table 3 depicts the preventive attitudes taken by the population regarding penile cancer in undergraduate students in the health area.

The above table shows that $93.9 \%$ carry out cleaning of the penis daily with soap and water, $91.2 \%$ use condoms in sexual relations; $97.4 \%$ perform hygiene of the penis after sexual intercourse and masturbation; $93 \%$ try to have good hygienic habits; $89.3 \%$ did not 
detect a penile lesion so far, $93.8 \%$ went to the doctor when they felt something and $99.1 \%$ did the penis inspection when they were in the shower.

Table 3 Analysis of preventive attitudes about penile cancer in undergraduate students in the health area. Goiás, 2018. $(n=114)$

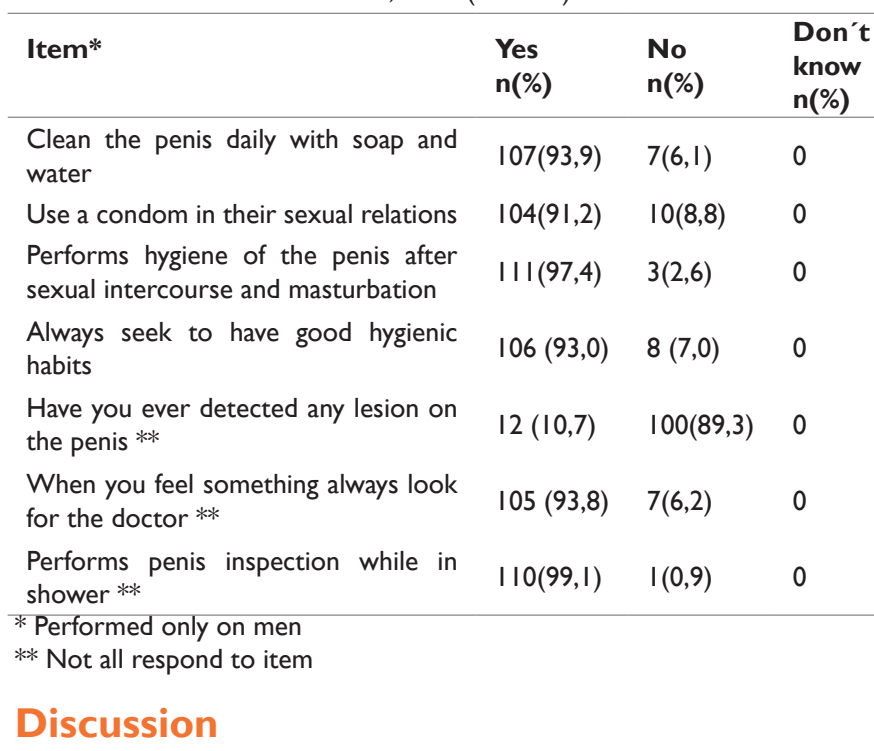

The socioeconomic and demographic characteristics identified in this study show that the students in the health area were in the mean age of 26-85 years, with the predominance of subjects with single civil status, the sample and predominance of the female gender, enrolled in the course nursing and Catholic religion. In the study it was observed that $93.1 \%$ of the participants disagree that penile cancer is only found in individuals over 50 years of age; in contradistinction with the National Institute of Cancer Jose de Alencar Gomes da Silva do Brasil (INCA), the same affirms that the penis cancer is a rare tumor, with a greater incidence in men from the 50 years, although it can reach also the most young. ${ }^{8,9}$

It is very important to highlight the concern of the students of the health area with the thematic passed, the study demonstrates the concern of the same in the promotion of their individual health and soon of the inputs that they attended when they were formed. Most students understand that risk factors such as: lack of intimate hygiene, and the presence of penile lesions for a long time are indicative of penile cancer, so the students' understanding is in line with the INCA statement that low socioeconomic and educational conditions, and poor intimate hygiene are predominant factors for the development of penile cancer. ${ }^{9}$ HPV has also been identified as a predominant risk factor. Scientific studies also suggest the association between infection by HPV (human papillomavirus) and penile cancer. ${ }^{9}$ A review study points out that the variability of the finding of the presence of HPV infection in association with penile carcinoma found variations between $15.0 \%$ and $46.3 \%$ in 9 studies that evaluated the presence of HPV in relation to the oncogenic process in the development of penile carcinoma. ${ }^{10}$

It has also been pointed out by students that promiscuity, bleeding and stench are relevant factors for the development of neoplasia and can lead to amputation of the penis. ${ }^{5,11}$ Symptoms generally include bleeding and stinging of the genitalia. All penile lesions, particularly those in which the patient presents the non-retractable foreskin, require special attention and should be investigated with suspected neoplasia. Biopsy and immunohistochemistry in these cases is an important form of diagnosis. In large lesions, the diagnosis is obtained by incisional biopsy. ${ }^{12,13}$ In general, there was a predominance of correct answers in all questions presented to undergraduate students, thus evidencing the predominance of students with a high level of knowledge $(72.5 \%)$ on penile cancer, followed by those with a medium level of knowledge $(26,1)$ on the subject.

The study shows that the understanding of the students in the health area is of great value even more and worrying because in Brazil the incidence of penile cancer represents $2 \%$ of all types of cancer that affect men, being more frequent in in the North and Northeast regions and with a prevalence rate in the year (2013) of 396 cases. ${ }^{9}$ The preventive measures like the one carry out cleaning of the penis daily with water and soap, to use condom in the sexual relations; hygiene of the penis after intercourse and masturbation; perform the inspection of the penis when in the bath, associated with having good hygienic habits and seek the doctor when they feel something, were measures listed by the students as a priority as prophylaxis in the detection of it. To prevent penile cancer, daily hygiene with soap and water is necessary, especially after sexual contact and masturbation. It is essential to educate the children, and the population about the intimate hygiene routines, which should be exercised every day. Phimosis surgery is a simple and quick intervention. This operation, called circumcision, is usually performed in infancy. Both circumcised and uncircumcised men reduce the chances of developing this type of cancer, with good hygiene habits. ${ }^{14}$

Men are more susceptible to certain pathologies when compared to women. This factor, associated with the precarious demand for health services, contributes negatively to prevention and health promotion, considering that, according to studies in this segment, they are seen as virtuous beings, immune to illness, a factor that influences the current statistics especially when related to penile cancer. ${ }^{15}$ The predominance of nursing students in the study is important because the nurse bears the role of multiplier of the national public health care policies developed in Brazil. As in the case of the Policies of Integral Attention to the Health of Man that has as priority the promotion of the health of the same and the early prevention of aggravations. ${ }^{14,16,17}$

The nurse has the function of creating habits in the population through health education for the promotion of human health, seeking men for the adherence of the service in order to create a link with the health unit for health promotion and prevention and then minimize and morbidity and mortality indexes. ${ }^{14,16,17}$

\section{Conclusion}

The study demonstrated compliance in general, there was a predominance of correct answers in all the questions presented to undergraduate students in the health area, thus evidencing the understanding of students with a high level of knowledge regarding the prevention of penile cancer. Early detection of condom use, daily hygiene and non-promiscuity of sexual partners are relevant points in the prevention and detection of the disease. The predominance of nursing in this study is extremely important because it is responsible in Brazil for the promotion and prevention of health through national health policies and the management of the Family Health Strategy (Estratégia Saúde da Família (ESF)), which represents the door of the Unified Health System (Sistema Único de Saúde (SUS)), which is free and has as its principles through this strategy the promotion, prevention and health education of the entire Brazilian population. In this way, public and prophylactic policies through health education are of extreme value in reducing the incidence of penile cancer. 


\section{Acknowledgements}

None.

\section{Conflict of interest}

The author declares that there is no conflict of interest.

\section{References}

1. Barros Érika Neves de, Melo Mônica Cristina Batista de. Câncer de pênis: perfil sócio-demográfico e respostas emocionais à penectomia em pacientes atendidos no Serviço de Psicologia do Hospital de Câncer de Pernambuco. Rev SBPH. 2009;12(1):99-111.

2. Guimarães JTF, Oliveira FBM, Silva MV da RS da, et al. Avaliação do conhecimento de homens acerca do câncer de pênis e práticas preventivas. Revista Eletrônica Acervo Saúde. 2017;(8):S803-S810.

3. Guimarães GC, Rocha RM, Zequi SC, et al. Penile cancer: epidemiology and treatment. Curr Oncol Rep. 2011;13(3):231-239.

4. Paiva EP, Motta MCS, Griep RH. Barriers related to screening examinations for prostate cancer. Rev Latino-Am Enfermagem. 2011;19(1):73-80.

5. Panis Carolina, Kawasaki Aedra Carla Bufalo, Pascotto Claudicéia Risso, et al. Revisão crítica da mortalidade por câncer usando registros hospitalares e anos potenciais de vida perdidos. Einstein (São Paulo). 2018;16(1):eAO4018.

6. Ministério da Saúde. Estimativas da incidência e mortalidade por câncer no Brasil. Rio de Janeiro: Ministério da Saúde/Inca; 2003.

7. Van Eyken EBBD, Moraes CL. Prevalência de fatores de risco para doenças cardiovasculares entre homens de uma população urbana do Sudeste do Brasil. Cad Saúde Pública. 2009; 25(1):111-123.
8. Souza, KW, Reis PED, Gomes IP, et al. Prevention strategies for testicular and penile cancer: an integrative review. Rev Esc Enferm USP. 2011;45(1):272-276.

9. INCA. Câncer de Pênis. 2018.

10. Carvalho NS, Kannenberg AP, Munaretto C, et al. Associação entre HPV e câncer peniano: revisão de literatura. DST- J bras Doenças Sex Transm. 2007;19(2):92-95.

11. Querino MS, Almeida SS, Oliveira SCS, et al. Ações da equipe de enfermagem na implementação da política de lésbicas, gays, bissexuais, travestis e transexuais- revisão de literatura. Rev Cient Sena Aires. 2017;6(1):46-58.

12. Cubilla AL. Carcinoma of the penis. Mod Pathol. 1995;8(1):116-118.

13. Pow-Sang MR, Benavente V, Pow-Sang JE, et al. Cancer of penis. Canc Contr J. 2002;9(4):305-314.

14. Brasil. Ministério da Saúde. Política Nacional de Atenção Integral a Saúde do Homem (princípios e diretrizes). Brasília, Novembro de 2008.

15. Vaz CAM, Souza GB, Moraes-Filho IM, et al. Contribuições do enfermeiro para a saúde do homem na atenção básica. Rev Inic Cient Ext. 2018;1(2):122-126.

16. MORAES FILHO, Iel Marciano de; SILVA, Antonio Márcio Teodoro Cordeiro, ALMEIDA, Rogério José de. AVALIAÇÃO do estresse ocupacional de enfermeiros da estratégia saúde da família. Revista Eletronica Gestão \& Saúde. 2018;9(3):335-343.

17. Silva RM, Heitkemper MM, Kimura CA, et al. Changes in nursing students' health one year after starting the nursing degree program. $J$ Cancer Prev Curr Res. 2018;9(2):81-87. 